\title{
Research on the Ability of Regional Industrial Sustainable Development
}

\author{
-From the Perspective of "Two-Oriented" Society
}

\author{
Haidong Li, Shanyong Wang, Dingtao Zhao \\ School of Management, University of Science and Technology of China, Hefei, China \\ Email: wsy1988@mail.ustc.edu.cn
}

Received May 19, 2012; revised June 24, 2012; accepted July 6, 2012

\begin{abstract}
In this paper, firstly, we construct the regional industrial sustainable development indicator system which are consist with resource, environment, technology and industrial economy efficiency levels and 16 indicators from the perspective of "two-oriented society"; Secondly, using the method of AHP to determine the weight of each indicator and evaluate the ability of industrial sustainable development of 30 regions in China; Finally, according to the results, we used the method of cluster analysis to put the regions into classification and then author put forward certain suggestions to improve the ability of industrial sustainable development of each region.
\end{abstract}

Keywords: Two-Oriented Society; The Ability of Industrial Sustainable Development; AHP; Industrial Structure Adjustment

\section{Introduction}

Resource-saving and Environment-friendly Society is short for "two-oriented society". It is a new kind of development model which put resource and environment into economy and society development in the context of new development situation and tasks that China faced recent years. The ultimate goal of "two-oriented society" is to achieve the coordinated and sustainable development with economy, resource, environment and society.

Industry is the most important industry in the whole national economy. There will be no society sustainable development if no industrial sustainable development and "two-oriented society" will never become true. The definition of industrial sustainable development in the context of "two-oriented society" is that on the one hand, the industrial development should meet the standard of "two-oriented society", on the other hand should meet the needs of economy and society development at present; At the same time there will be no intimation to the development of economy and society in the future. The degree of industrial sustainable development is higher, the ability of industrial sustainable development is stronger, or more weaker. The efficiency of Chinese industry is lower in the long time, we input more but output lower. The structure of industry is not the best, industry use up lots energy and resource and the ability of industrial sustainable development is weak. There is no common standard to evaluate the ability of industrial sustainable development. In this paper, the author constructed regional industrial sustainable development indicator system in the context of "two-oriented society" and evaluated the ability of industrial sustainable development of 30 regions in China.

\section{Literatures}

The concept of sustainable development firstly proposed in the report of "Our Common Future" in the United Nations World Commission on Environment and Development (WCED) in 1987. It defined sustainable development as not only meet the current needs, but also not to posed a hazard to meet the needs of future generations development [1]. With the development of economy and society, foreign scholars began to introduce the concept of sustainable development to the industrial areas and formed the concept of industrial sustainable development. Some scholars began to study the industrial sustainable development, such as Hilson Gavin and Busu Arun J. (2003) [2] designed the indicator system to evaluate the mining industry sustainable development. Raymond P. Cote and Yiping Fang (2007) [3] analyzed the situation of the development of Chinese industry and pointed out the factors of restrictions on Chinese industry to achieve sustainable development. They think that some measures should be taken from the government, business, international cooperation, education, finance and other areas to improve the ability of industrial sus- 
tainable development.

In China, research on industrial sustainable development especially evaluate the ability of industrial sustainable development is still in infancy, the research literature is little. Xihong Qian and Yongfu Yang (2009) [4] defined the resource-saving and environment-friendly industrial connotation and constructed 28 indicators from the aspects of resource-saving, environment-friendly and the ability to support industrial development to evaluate the degree of "two-oriented society" of industry and take Guangdong province as an example to analyze. According to the result, the author put forward certain suggestions to industrial structure adjustment. Feng Li (2008) [5] constructed 12 indicators from the aspects of economy development capacity, scientific and technological progress capacity, human resource efficiency capacity, resource utilization capacity and the ability of environmental capacity, used the method of factor analysis to evaluate the degree of regional industrial sustainable development of China. Based on the results, the author thought the difference of natural resources, the ability of government services, the ability of technological innovation and the degree of the market were the main reasons that caused the regional differences in the degree of industrial sustainable development. De Zhou and Yijun Yuan (2008) [6] thought resources, environment, technology and economic growth ways are the determinants of industrial sustainable development, constructed indicators from the aspects of the sustainability of industrial development, social and industrial development coordination, resource use sustainability and ecological sustainability to evaluate the ability of industrial sustainable development in the context of "two-oriented society" of Dalian. Qian Wang (2008) [7] used the method of factor analysis to evaluate the ability of industrial sustainable development of Jiangsu province from the aspects of the degree of social development, environmental development and environmental carrying capacity. She pointed out that scientific and technological progress played an important role in Jiangsu Province to improve the ability of industrial sustainable development, at the same time she put forward some suggestions to promote the ability of sustainable development of Jiangsu province. Liming Xiong (2008) [8] took Jiangxi province as an example, systematically analyzed the status and the plight of industrial development in Jiangxi province. He believed industry must go the road of sustainable development in the context of "two-oriented society" and put forward countermeasures and suggestions.

From the analysis we can see that recently study mainly focus on measure the degree of "two-oriented society" of industry, describe the status of industrial sustainable development and how to achieve industrial sustainable development; At the same time, most studies based on individual areas research. The study is little in how to assess the ability of industrial sustainable development of all the regions of China in the context of "two-oriented society".

In this paper, the author combined the research methods of relevant scholars and constructed the indicators to asses the ability of industrial sustainable development from the aspects of resources, environment, technology, industrial economic efficiency, then evaluated the ability of industrial sustainable development of 30 regions in China. According to the result, author put forward certain suggestions to improve the ability of industrial sustainable development for each region.

\section{An Empirical Study to Asses the Ability of Industrial Sustainable Development}

\subsection{Constructed the Indicator System}

To full and scientific evaluated the ability of industrial sustainable development of 30 regions in China, we refer the previous research results and follow the principle of practical, scientific, data availability and hierarchy to constructed the indicator system.

To achieve the industrial sustainable development, firstly industry must meet the standard of "two-oriented society”. Industry which consume resources much and serious pollution is not possible to achieve sustainable development. Secondly, technological progress is the driving force to industrial sustainable development.The higher level of technology to industry, the stronger driving force to industrial sustainable development. Industrial economic efficiency is also the key factors of industrial sustainable development which mainly reflects the input-output ratio. If input low but output high, the industrial economic efficiency will be much higher, the driving force for development will be much stronger so the ability to achieve sustainable development will be stronger, too.

Based on this point, the paper constructed the indicator system from the aspects of environmental indicators (F1), resource indicators (F2), technical indicators (F3) and the industrial economic efficiency indicators (F4) to assess the ability of industrial sustainable development of 30 regions in China. Each indicator can be refined to four indicators and there are 16 indicators. Table 1 shows the specific indicators.

\subsection{Determine Weight of Each Indicator}

The weight of indicators reasonable or not determine the results right or wrong. In this paper, we use the method of AHP to determine the weight of each indicator. AHP is the method which by comparing the relative importance of each indicator at the same level and then determine the weight of each indicator. First of all, judgment 
matrix must be built. We usually use the method of 1 - 9 ratio scaling and compare the relative importance of indicators. Secondly, determine the weight of each indicator. Finally, test the consistency:

$$
C R=\frac{C I}{R I}=\frac{\left(\lambda_{\max }-n\right) /(n-1)}{R I}
$$

if $C R<0.1$ then pass the test or continue the process until $C R<0.1$. Table 2 shows the weight of indicators.

\subsection{Data Processing}

To evaluate the ability of industrial sustainable development of regions in China, we choose the data of year 2008 to analyze and choose 30 provinces (Except Hong Kong, Macao, Tibet and Taiwan) in China as the sample.

Difference between the value of indicator's unit and magnitude will affect the results, so we need for standardization for each indicator value. Indicator can be divided into positive and negative. Positive indicators are the indicator which the value is bigger, the efficiency is better. Others are the negative indicators. To different indicators, the method of standardization is different.

To positive indicators, the method of standardization is:

$$
X_{i j}^{\prime}=\frac{X_{i j}-\overline{X_{j}}}{S_{j}}
$$

To negative indicators, the method of standardization is:

$$
X_{i j}^{\prime}=\frac{\overline{X_{j}}-X_{i j}}{S_{j}}
$$

$(i=1,2,3, \cdots, 30, j=1,2, \cdots, 16)$.

$X_{i j}$ represents the region $i$ and the value of indicator $j$; $X_{i j}^{\prime}$ represents the value of standardization; $X_{j}$ represents the average value of indicator $j$; $S_{j}$ represents the

\begin{tabular}{|c|c|c|}
\hline Target unit & Four aspects & Specific indicators \\
\hline \multirow{15}{*}{$\begin{array}{l}\text { The ability } \\
\text { of industrial } \\
\text { sustainable } \\
\text { development }\end{array}$} & \multirow{4}{*}{ F1: Environmental indicator } & $\mathrm{X} 1$ : The ratio of meet the standards of industrial wastewater discharge (\%) \\
\hline & & X2: The ratio of comprehensive utilization of industrial solid waste (\%) \\
\hline & & X3: The ratio of green coverage of built-up areas (\%) \\
\hline & & X4: The output value of comprehensive utilization of waste products (ten thousands) \\
\hline & \multirow{4}{*}{ F2: Resource indicator } & X5: Unit GDP energy consumption (Tons of standard coal/ten thousands) \\
\hline & & X6: Energy consumption per unit of industrial added value (Tons of standard coal/ten thousands) \\
\hline & & X7: Unit of GDP power consumption (KWh/ten thousands) \\
\hline & & X8: Ten thousands in GDP of industrial wastewater discharge (tons/ten thousands) \\
\hline & \multirow{3}{*}{ F3: Technological indicator } & X9: Number of R \& D personnel (person) \\
\hline & & X10: R \& D funding (ten thousands) \\
\hline & & X12: Financial investment to develop new products (ten thousands) \\
\hline & \multirow{4}{*}{$\begin{array}{l}\text { F4: Industrial economic } \\
\text { efficiency indicator }\end{array}$} & X13: Total assets contribution rate (\%) \\
\hline & & X14: Asset-liability ratio (\%) \\
\hline & & X15: Turnover of current assets (times/year) \\
\hline & & X16: Ratio of profits to cost (\%) \\
\hline
\end{tabular}
standard deviation of indicator $j$.

Table 1. Indicator system of industrial sustainable development.

\begin{tabular}{|c|c|c|c|c|c|c|c|c|}
\hline Four aspects & \multicolumn{4}{|c|}{ F1: Environmental indicator } & \multicolumn{4}{|c|}{ F2: Resource indicator } \\
\hline weight & \multicolumn{4}{|c|}{0.269} & \multicolumn{4}{|c|}{0.248} \\
\hline Specific indicators & $\mathrm{X} 1$ & $\mathrm{X} 2$ & X3 & $\mathrm{X} 4$ & X5 & X6 & X7 & X8 \\
\hline weight & 0.286 & 0.343 & 0.2 & 0.171 & 0.303 & 0.213 & 0.242 & 0.242 \\
\hline Four aspects & \multicolumn{4}{|c|}{ F3: Technological indicator } & \multicolumn{4}{|c|}{ F4: Industrial economic efficiency indicator } \\
\hline weight & \multicolumn{4}{|c|}{0.333} & \multicolumn{4}{|c|}{0.15} \\
\hline Specific indicators & X9 & $\mathrm{X} 10$ & $\mathrm{X} 11$ & $\mathrm{X} 12$ & X13 & $\mathrm{X} 14$ & $\mathrm{X} 15$ & $\mathrm{X} 16$ \\
\hline weight & 0.275 & 0.234 & 0.234 & 0.257 & 0.29 & 0.241 & 0.224 & 0.245 \\
\hline
\end{tabular}

Table 2. The weight of indicators. 


\subsection{Evaluate the Ability of Industrial Sustainable Development of Regions in China}

We can calculate the scores according to the value of standardization and weight. The method of calculate scores of four indicators can be listed as follows:

$$
\begin{gathered}
F_{1 i}=\sum_{j=1}^{4} W_{i j} X_{i j}^{\prime}, \\
F_{2 i}=\sum_{j=5}^{8} W_{i j} X_{i j}^{\prime}, \\
F_{3 i}=\sum_{j=9}^{12} W_{i j} X_{i j}^{\prime}, \\
F_{4 i}=\sum_{j=13}^{16} W_{i j} X_{i j}^{\prime} \quad(i=1,2,3, \cdots, 30)
\end{gathered}
$$

$F_{1 i}, F_{2 i}, F_{3 i}, F_{4 i}$, represent the scores of four indicators of region I respectively; $X_{i j}^{\prime}$ represents the region I and the standardization value of indicator $j$; $W_{i j}$ represents the weight.

After calculate the scores of four indicators, we can calculate the comprehensive scores of each region. Based on the scores of each region, we can judge the ability of industrial sustainable development.

The model of comprehensive scores of each region is:

$$
F_{i}=\sum_{k=1}^{4} a_{k i} F_{k i}
$$

( $i=1,2,3, \cdots, 30 ; k=1,2,3,4)$.

$F_{i}$ represents the comprehensive score of the ability of industrial sustainable development of region I; $F_{k i}$ represent the scores of four indicators of each region; $a_{k i}$ represents the weight.

According to the model, we can calculate the comprehensive scores of 30 regions in China. Table 3 shows the scores.

Table 3. Comprehensive scores of 30 regions in China.

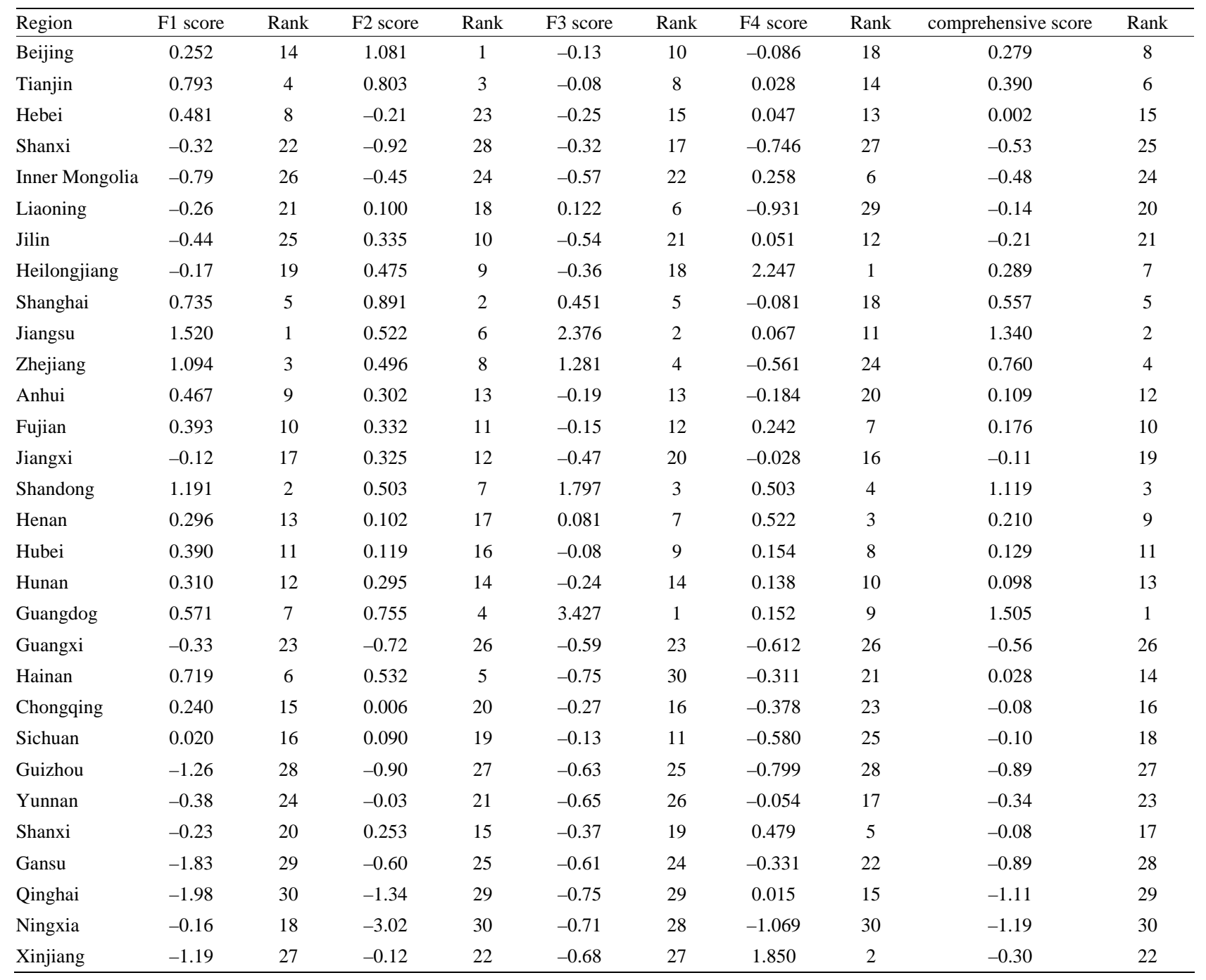


In the table, the scores of some regions are negative. It is caused by standardization. The negative scores don't mean that the region without any industrial sustainable development ability. The scores are negative or positive just mean the position relationship between the averages. We usually considered the average of industrial sustainable development ability is zero.

\subsection{Analysis}

From the analysis above, we can see that the ability of industrial sustainable development is different in different provinces (as Figure 1 shows). Even in the same region there is difference. The score in some indicators is well while in other indicators is worse.

From Figure 1 and Table $\mathbf{3}$ we can see that provinces with highest scores are Guangdong, Jiangsu, Shandong, Shanghai and Zhejiang. Provinces with the lowest scores are Ningxia, Gansu, Guizhou and Qinghai. Scores in terms of environmental indicators, Jiangsu, Zhejiang, Shandong get the highest scores and Guizhou, Gansu, Qinghai get the lowest scores. Scores in terms of resource indicators, Beijing, Shanghai, Tianjin get the highest scores and Shanxi, Qinghai, Ningxia get the lowest scores. Scores in terms of technical indicators, Guangdong, Jiangsu, Shandong get the highest scores and Ningxia, Qinghai, Hainan get the lowest scores. Scores in terms of industrial economic efficiency indicators, Heilongjiang, Xinjiang, Henan get the highest scores and Guizhou, Liaoning, Ningxia get the lowest scores.

To compare and analyze the ability of industrial sustainable development intuitively and clearly, we use group average method of SPSS 17.0 to cluster analysis. According to the results of running the software, China's
30 provinces can be divided into 3 categories. Table 4 shows the results.

Specifically, the first category is basically on the economically well developed eastern coastal provinces which get the strongest ability of industrial sustainable development. The second category is basically on the northeast, southwest, central provinces which get medium ability of industrial sustainable development. The third category is basically on the northwest and southwest provinces which get weakest ability of industrial sustainable development. The standard of classification is broadly in line with the level of economic development.

\section{Suggestions for Improve the Ability of Industrial Sustainable Development for Each Region}

\subsection{Suggestions for First Category Provinces}

To first category provinces, the ability of industrial sustainable development is the most strongest and the economy is well developed. The scores in environmental indicators, resource indicators and technical indicators are the highest. Industrial development is basically satisfied the requirements of "two-oriented" society. But the scores in economy efficiency indicators are low. So in the future we need to further expand the scale of the industry, strengthen the leading industry and achieve the economies of scale; In the industrial enterprises using the new style of leadership and management systems to improve employee motivation; Accelerate the pace of cash flow, improve the efficiency of fund utilization; Increased capital investment to develop high-tech industries and promote industrial structure optimization

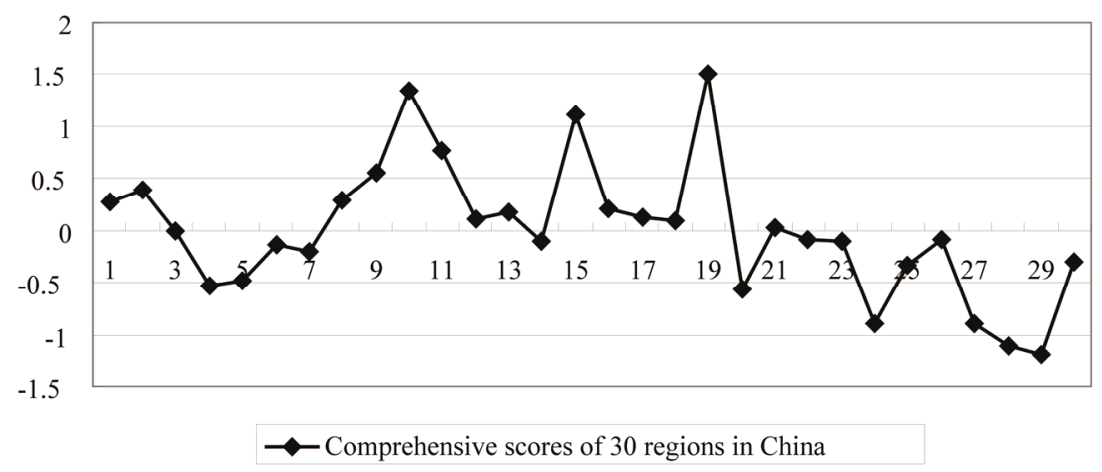

Figure 1. Comprehensive evaluation of industrial sustainable development.

Table 4. Industrial sustainable development classified chart.

\begin{tabular}{cl}
\hline Categories & Provinces \\
\hline First category & Shanghai, Jiangsu, Zhejiang, Guangdong, Shandong \\
Second category & Beijing, Tianjin, Hebei, Shanxi, Inner Mongolia, Liaoning, Jilin, Heilongjiang, Anhui, Fujian, \\
Third category & Jiangxi, Henan, Hubei, Hunan, Guangxi, Hainan, Chongqing, Sichuan, Yunnan, Shanxi \\
& Xinjiang, Ningxia, Qinghai, Guizhou, Gansu \\
\hline
\end{tabular}


and upgrading.

\subsection{Suggestions for Second Category Provinces}

The ability of industrial sustainable development for second category provinces is weaker compared with first category provinces. To Beijing and Tianjin, in the future need to further increase science, technology and capital investment, improve resource use efficiency and economy efficiency of enterprises, at the same time eliminate backward production capacity and develop high-tech industries. Liaoning, Jilin and Heilongjiang are the old industrial bases in northeast China, industrial restructuring has achieved initial success in the support of national policy. In the future should further strengthen the leading industries, improve economic efficiency of enterprises and intensity governance to heavily polluting enterprises. Central provinces can make full use of national strategies "Rise of Central China”, get more capital, technology, policy support to increase R \& D investment and promote optimization and upgrading of industrial structure. Part of the provinces can accept the transfered industries of developed eastern provinces. Other areas the industrial structure should be further adjusted, coordination of light and heavy industry development, eliminate backward production capacity, improve the emission standard levels of industrial enterprises and improve the level of "twooriented society" of industry; Increase financial and technological investment, foster new industries; Improve resource use efficiency and to develop the recycling economy.

\subsection{Suggestions for Third Category Provinces}

To third category provinces, they mainly located in the western less developed provinces with low level of industrial development and sustainable development is poor. To improve the ability of industrial sustainable development, nowadays should develop the leading industries and through leading industries to driven other related industries to development; For the status of inefficient use of resources, enterprises should increase capital investment, full play the role of universities, research institutes to improve the technological content of industrial enterprises and economy efficiency of enterprises. In the development of industry, we should focus on improving the level of "two-oriented society" of industry and focus on the environment, resources and industry coordinated development.

\section{REFERENCES}

[1] World Commission on Environment and Development,
“Our Common Future,” Jilin People’s Press, Changchun, 1997.

[2] H. Gavin and A. J. Busu, "Devising Indicators of Sustainable Development for the Mining and Minerals Industry: An Analysis of Critical Background Issues,” International Journal for Sustainable Development \& World Ecology, Vol. 4, No. 4, 2003, pp. 545-557.

[3] R. P. Cote and Y.-P. Fang, "Industrial Sustainability in China: Practice and Prospects for Eco-Industrial Development,” Journal of Environmental Management, Vol. 83, No. 4, 2007, pp. 315-328.

[4] X. H. Qian, Y. F. Yang and W. L. Xu, "Resource Saving and Environmental Friendly Industrial Evaluation Indicator Cluster," Forum on Science and Technology in China, Vol. 6, No. 4, 2009, pp. 73-78.

[5] F. Li, "Evaluation the Level of Regional Industrial Sustainable Development,” Business Modernization, Vol. 29, No. 3, 2008, pp. 208-209.

[6] D. Zhou and Y. J. Yuan, “Comprehensive Evaluation on Industrial Sustainable Development under the Constraint of Resource and Environment," Science Technology and Industry, Vol. 9, No. 5, 2008, pp. 38-41.

[7] Q. Wang, "Based on Scientific and Technological Progress of Industrial Sustainable Development in Jiangsu Province,” Master Dissertation, Nanjing University, Nanjing, 2008.

[8] J. Y. Zhang, “The Research of Industrial Sustainable Development for Coastwise Region of Chang Jiang River in Jiangsu Province-At the Base of Analysis for Resource and Environment Restriction,” Master Dissertation, Nanjing University, Nanjing, 2006.

[9] L. M. Xiong, "Suggestion for Industrial Sustainable Development of Jiangxi Province under the Condition of Resource and Environmental Constraints," Finance and Economy, Vol. 2, No. 2, 2008, pp. 55-58.

[10] Q. Wang and S. N. Li, "Thoughts on Optimization and Upgrading of Industrial Structure in China,” Economics and Management, Vol. 1, No. 5, 2004, pp. 24-26.

[11] H. J. Zhang and Z. G. Gao, "Problems of Industry Transformation Based on Sustainable Development Ability of Resource-Based City-A Case Study on Karamay City, Xinjiang,” Arid Land Geography, Vol. 3, No. 7, 2008, pp. 409-413.

[12] X. J. Jia, "Industrial Restructuring of Resource and Environmental Constraints under the Two-Oriented Society,” Theory and Practice, Vol. 3, No. 1, 2008, pp. 86-88.

[13] S. W. Ye, Z. M. Liu and M. L. Fu, "Industry Transformation and Sustainable Development of Western ResourcesBased City,” Exploration, Vol. 5, No. 6, 2003, pp. 116118.

[14] J. Glasson, R. Therivel and A. Chadwick, "Introduction to Environmental impact assessment,” Rout-ledge, London, 2005. 